\title{
The Acquisiton of Word-final Clusters in French*
}

\section{Katherine Demuth}

Brown University. Cognitive and Linguistic Sciences

Box 1978. Providence, RI 02906

Katherine_Demuth@brown.edu

\section{Margaret Kehoe}

University of Hamburg. Research Centre for Multilingualism

Max-Brauer-Allee 60. D-22765 Germany

kehoewinkler@gmx.ch

\begin{abstract}
The structure of French syllables has long been controversial, particularly with respect to the status of word-final consonants. Some researchers suggest that word-final consonants are syllabified as codas, whereas others propose that these are onsets of empty-headed syllables. This raises questions regarding the nature of syllabic representations in children's developing French, a topic that has received little attention. This study examines 2-year-olds' elicited productions of wordfinal obstruent-liquid (OL) clusters, and compares these with the acquisition of word-initial OL clusters. The acquisition of singleton word-final consonants is also discussed. Although wordfinal clusters are acquired later than both word-initial clusters and word-final singletons, the error patterns are the same, with earlier acquisition and preservation of obstruents. A few children exhibit final vowel epenthesis, raising the possibility that some French-speaking children may syllabify word-final consonants as onsets. The paper concludes with a discussion of the crosslinguistic implications of these findings, identifying several areas for further research.
\end{abstract}

Key words: phonological acquisition, syllable structure, clusters.

\section{Table of Contents}

\section{Introduction 6. Discussion}

2. The acquisition of singleton word-final consonants in French

3. The acquisition of consonant clusters

7. Conclusion

Appendix

References

4. The study

5. Results

* This study was supported by the National Institute of Mental Health Grant \# IRO IMH60922 awarded to the first author. We thank two anonymous reviewers for helpful comments, and all those who assisted with various aspects of the study: Manuel Barcelos, Emilie Charillon, Jennifer Culbertson, Christophe dos Santos, Geraldine Hilaire-Debove, Harriet Jisa, Cecilia Kirk, Elizabeth McCullough, Valerie Regol, and Yvan Rose. 


\section{Introduction}

The syllabic status of French word-final consonants has long been controversial, reflecting different theoretical positions in the field (e.g., Hammond, 1999; Harris, 1994; Kaye, 1990; Kaye, Lowenstamm, \& Vergnaud, 1990). Some researchers suggest that French can have a bipositional (bimoraic) rhyme, where a singleton coda consonant is permitted (e.g., Bouchard, 1980; Dell, 1995; Féry, 2003; Rialland, 1994; Scullen, 1997; Tranel, 1987). This structure is shown in (1a). Others agree that the French rhyme is maximally bipositional, but that the second rhyme slot can only be occupied by a sonorant consonant. Plénat's (1987) justification for this proposal comes from the fact that sonorant consonants tend to be 'fixed', typically being realized on the surface, whereas stops can be 'latent', showing surface alternation, generally appearing only when followed by a vowel. Still others have proposed that all French singleton word-final consonants are syllabified as onsets of empty-headed syllables regardless of sonority (Charette, 1991; Nikièma, 1999), as illustrated by the structure in (1b). How, then, is a learner to determine the syllable structure of singleton word-final consonants in French?

(1) Representation of word-final singleton consonants for lexical item botte 'boot'

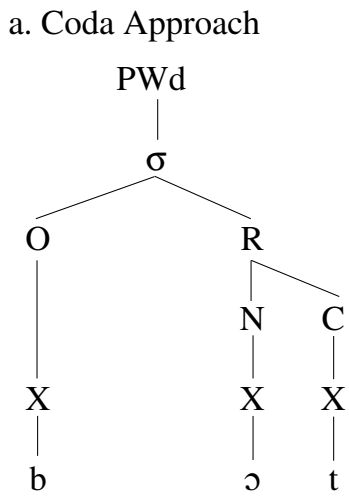

b. Onset Approach

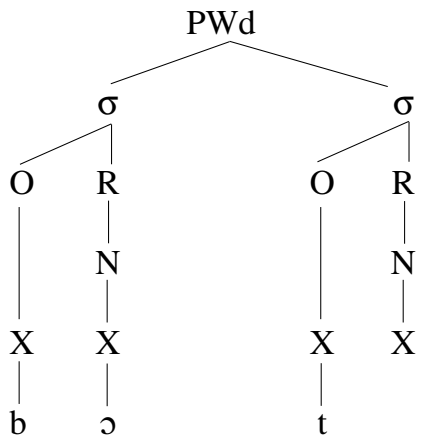

The linguistic facts of French provide support for both the 'coda' and 'onset' representational approaches. On the one hand, French vowel distribution supports a coda approach to French syllable structure. In many dialects of French, tense vowels typically appear in open syllables and lax (mid) vowels in closed syllables. This tendency, known as règles de position, suggests that at least some types of wordfinal consonants function as codas (e.g., Dell 1973; Selkirk 1972; Tranel 1995; also Féry, 2003 and others). On the other hand, stress assignment and final schwa epenthesis provide some support for an onset approach to word-final consonants in French. Stress assignment is predictable, the final full vowel receiving stress regardless of the presence of the word-final consonant. In other words, stress assignment in French is independent of syllable weight. In addition, French speakers often epenthesize a vowel (schwa or the mid front unrounded vowel [œ]) follow- 
ing production of a word-final consonant. Both of these factors suggest that singleton word-final consonants may not be functioning as codas, but as onsets. Again, this raises questions about how the syllable structure of French is learned, and if a better understanding of the acquisition process might also shed light on the syllable structure of French.

The issue becomes more complex when one considers the representational status of word-final consonant clusters. Consider the Sonority Sequencing Principle (SSP), which prohibits increases in sonority from the nucleus to the edges of the syllable (2), and the Sonority Hierarchy (Clements 1990) in (3), which treats liquids as being more sonorous than obstruents (fricatives and stops).

(2) Sonority Sequencing Principle (SSP)

The level of sonority must not increase from the nucleus to the edges of the syllable.

(3) Sonority Hierarchy:

glides $(\mathrm{G})>$ liquids $(\mathrm{L})>$ nasals $(\mathrm{N})>$ fricatives $(\mathrm{F})>$ stops $(\mathrm{S})$

Thus, a word-final obstruent-liquid (OL) sequence that violates the SSP, such as in the word lettre /lets/ 'letter', will be phonologically marked if it is contained within the coda of a syllable. However, some researchers do assume that wordfinal OL sequences appear as codas (Tranel, 1987). Support for this position comes from several dialects of French (e.g., Québec French, Haitian French, and even standard French), where word-final OL clusters may undergo liquid reduction (Casagrande, 1984; Côté, 2000; 2004; Charette, 1991; Nikièma, 1999; van Oostendorp, 2000), a process that would not be expected if these were onsets. This is shown in (4) (examples are taken from Québec French (Côté, 2004: 9)).

$\begin{array}{llll}\text { (4) } \underline{\text { livre }} & / \text { livb/ } & {[\text { liv }]} & \text { 'deliver + PRES' } \\ \underline{\text { souffle }} & / \text { sufl/ } & \text { [suf }] & \text { 'blow + PRES' }\end{array}$

One explanation for this type of reduction process is the SSP, which seeks to avoid a rise in sonority within the coda. Perhaps learners may also delete such liquids, leaving the less sonorant consonant as the coda. However, the fact that the liquid can delete in Québec French, but not the obstruent, might also be explained by perceptual salience. The consonant immediately following the vowel may benefit from cues present in the vocalic transitions that make it perceptually stronger (Côté, 2000; 2004). Liquids are often also devoiced (cf. Féry, 2003) and this may further enhance a tendency for reduction. In addition, deletion of the most sonorous element of a consonant cluster is a common pattern in cross-linguistic and developmental grammars (Barlow, 1997; Gnanadesikan, 2004), leading us to expect that the same might be true for French.

Another approach which also assumes a monosyllabic representation of OL clusters links the entire word-final cluster directly to the prosodic word node, creating an extrasyllabic consonant cluster, thereby avoiding violations of the SSP 
altogether (Rialland, 1994). Although the perceptual issues would be the same here, the representational issues are quite different, and it is not clear what one might predict learners would do. On one hand, the lack of SSP violations would be a plus. On the other hand, perhaps 'extraprosodic' elements are more marked, and would be dispreferred by learners (though English word-final obstruent $+/ \mathrm{s}$ / clusters, which are often assumed to contain an extraprosodic appendix, are some of the earliest acquired (Kirk \& Demuth, 2005)).

In contrast to these coda and other monosyllabic accounts, researchers working within the general framework of Government Phonology propose that word-final OL sequences in French are syllabified as complex onsets of empty-headed syllables (Charette, 1991; Dell, 1995; Féry, 2003; Nikièma, 1999). Evidence for this form of syllabification comes from the patterning of long vowels in Québec French. A vowel may be lengthened or diphthongized before an OL cluster (5a) and before a singleton word-final consonant (5b) but not before a liquid-obstruent (LO) cluster (5c). Charette (1991) interprets this pattern as revealing that neither OL clusters nor singleton word-final consonants are syllabified within a branching rhyme, but rather form onsets of empty-headed syllables. The LO cluster receives a different syllabification, however. The liquid is syllabified as a coda and only the obstruent forms the onset of an empty-headed syllable. This is consistent with phonotactic restrictions in French: a LO cluster is not an acceptable onset cluster word-initially in French, so it is unlikely to be one word-finally. Perhaps learners are sensitive to the distribution of long vowels and following consonants early in the learning process, and develop a syllabification algorithm similar to that proposed by Charette (1991).

(5) Vowel lengthening in Québec French (Charette, 1991: 124)

\begin{tabular}{|c|c|c|c|}
\hline a. $\frac{\text { sable }}{\text { pauvre }}$ & $\begin{array}{l}\text { [sa:bl] } \\
\text { [po:vs] }\end{array}$ & [sa $\left.{ }^{\mathrm{u}} \mathrm{bl}\right]$ & $\begin{array}{l}\text { 'sand' } \\
\text { 'poor' }\end{array}$ \\
\hline b. $\frac{\text { bête }}{\underline{\text { rage }}}$ & $\begin{array}{l}\text { [be:t] } \\
\text { [ва:3] }\end{array}$ & $\begin{array}{l}{\left[\mathrm{ba}^{\mathrm{i}} \mathrm{t}\right]} \\
{\left[\mathrm{вa}^{\mathrm{u}} 3\right]}\end{array}$ & $\begin{array}{l}\text { 'stupid' } \\
\text { 'madness' }\end{array}$ \\
\hline c. $\frac{\text { forte }}{\text { parc }}$ & $\begin{array}{l}{[\text { fэьt }]} \\
\text { [равk] }\end{array}$ & $\begin{array}{l}*[\text { fo:st }] \\
*[\text { pa:sk] }\end{array}$ & $\begin{array}{l}\text { 'strong' } \\
\text { 'park' }\end{array}$ \\
\hline
\end{tabular}

Additional evidence for an onset syllabification of OL clusters includes the fact that, as already noted for singletons, word-final OL clusters are often produced with a final epenthetic schwa (e.g., lettre -> [letьə] 'letter'). (Note, however, that this would also be consistent with the obstruent being syllabified as a coda, and the liquid being syllabified as an onset (O.L) (see below for further discussion)). Féry (2003) supports an onset analysis of word-final OL clusters in terms of optimalitytheoretic constraints (Prince \& Smolensky, 1993), maximizing the onset to the empty-headed syllable. Perhaps children take a similar approach. The representation of word-final OL clusters prosodified as either the coda or as the onset to an empty-headed syllable is given in (6a) and (6b) respectively (the former is adapted from Tranel (1987: 136)). 
(6) Representation of word-final OL clusters in French - lettre 'letter'

a. Coda Approach

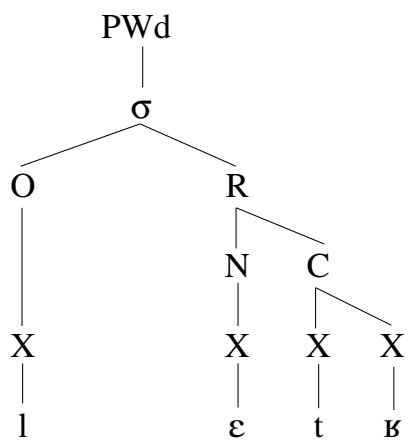

b. Onset Approach

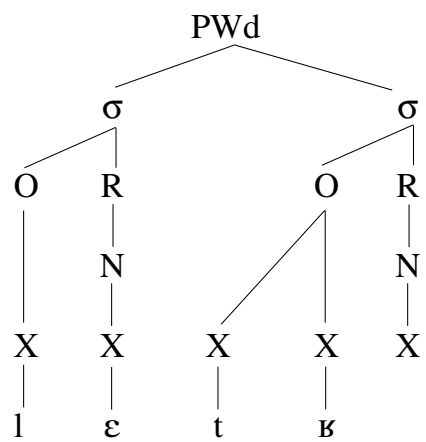

Apart from a syllable-final and a syllable-initial representation of OL sequences, some accounts of the French sound system suggest that the final liquid in OL clusters is syllabic (Casagrande, 1984). Although the phonetic realization of the final liquid may appear to be syllabified, it differs greatly from the realization of syllabic liquids in other languages, where the syllabic consonant occupies the nucleus of the syllable. This is shown for the English word letter in (7a). However, learners might break the cluster into two parts, syllabifying the obstruent as a coda, and the liquid as an onset (O.L) (7b).

(7) Possible syllabifications of final OL sequences.

a. Syllabic liquid: English letter

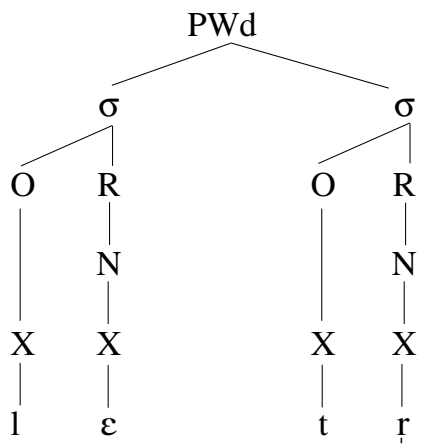

b. Coda+Onset: French lettre 'letter'

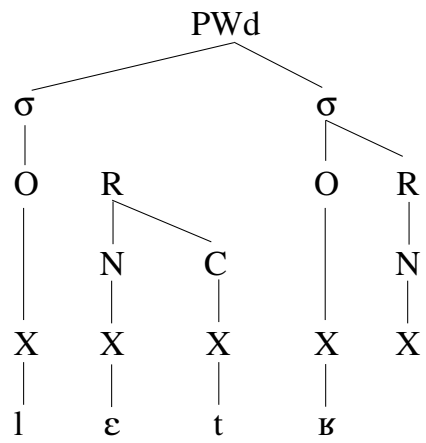

The purpose of this study was therefore to examine the acquisition of French word-final consonant clusters. Given the ongoing debate regarding the syllabic representation of both French word-final consonants and consonant clusters, it may be difficult for learners to determine what the correct syllabification is. This might be manifested in later acquisition of these structures. We might also expect to find 
individual variation, with learners showing different patterns of development. Of course, determining the syllabic structures children assume may be an impossible task if the facts of the adult language can be interpreted in several different ways. Nonetheless, we hope that by examining the development of French word-final clusters, we might better understand how these are acquired, and perhaps also shed light on their structure. Before proceeding to the study, we first review the literature on the acquisition of singleton word-final consonants in French, and then turn to a discussion of the acquisition of clusters more generally.

\section{The acquisition of singleton word-final consonants in French}

As illustrated in the discussion above, many of the issues relating to the acquisition of French singleton word-final consonants and word-final clusters are the same. It has been proposed that both can be realized within the syllable coda, or that both can be represented as onsets to empty-headed syllables. It has also been proposed that some singleton word-final consonants (e.g., sonorants) can be syllabified as codas, but that others (e.g., obstruents) must be syllabified as onsets to empty-headed syllables (Plénat, 1987). If this were the case we might expect to find a different pattern of acquisition for word-final singleton obstruents than for word-final singleton nasals and liquids.

Goad and Brannen (2003) suggest that onsets to empty-headed syllables are less marked than codas, and will therefore be acquired earlier. Furthermore, they suggest that the apparent early acquisition of codas, even in languages like English, is due to the fact that the codas are actually onsets to empty-headed syllables. As support for their claim they point to the fact that English-learning children often follow a target word-final consonant with a vowel (CVC > CVCV), or exhibit a strange release on the final consonant (e.g., aspiration). They take both as evidence that learners treat these consonants as onsets (though see Demuth, Culbertson \& Alter (in press) for a different, articulatory view). Rose (2000, 2003) proposes the same for French. Note, however, that it is also possible that onsets to empty-headed syllables may be acquired later than canonical onsets due to the fact that the best onsets are followed by a vowel (cf. Demuth, 1995, Gnanadesikan, 2004). That is, contrary to proposals by Goad and Brannen (2003), it is possible that onsets to empty-headed syllables are more marked than codas.

In this section we review experimental findings regarding French-speaking children's acquisition of singleton word-final consonants, providing a baseline for assessing the acquisition of word-final clusters. The children in both studies lived in Lyon, France. Thus, any differences in the results are not due to dialectal variation.

The singleton word-final consonant study was conducted with 15 children (9 girls and 6 boys) ranging in age from 1;8-2;9 (mean age 2;2) (Hilaire-Debove \& Kehoe, 2004). Children were asked to identify pictures of 29 familiar words commonly found in French-speaking children's vocabularies (17 monosyllables and 12 disyllables). Sessions lasted approximately 30 minutes, with multiple productions of the same word included for analysis. Most word-final consonants were target-like, 
thus a word-final consonant was classified as correctly produced if a consonant was produced. Overall, the children were $85 \%$ correct at producing word-final consonants in a target-like manner, though the older children tended to produce more coda consonants than the younger children. Performance was best on the least sonorant stop consonants (90\%), very good on fricatives (85\%) and nasals $(87 \%)$, and less good on the more sonorant liquid consonants (77\%). The production of word-final liquids was much better for the older children, suggesting an effect of segmental development, especially for $/ \mathrm{r} /$.

These findings indicate that French-speaking children are still acquiring wordfinal consonants by the age of 2, but that by the age of 2;6 most are producing word-final singleton consonants over $80 \%$ of the time, especially in monosyllabic words. Furthermore, French-speaking 2-year-olds are most accurate at producing word-final voiceless stops, and least accurate at producing word-final liquids. Although English-speaking children typically reach $80 \%$ of coda production several months before the age of two (cf. Demuth, et al., in press; Kirk \& Demuth, 2005), they also show earlier acquisition of (voiceless) stops, and later acquisition of liquids (Kehoe \& Stoel Gammon, 2001). However, stops are the most frequent codas in English (Stites, Demuth, \& Kirk, 2004), whereas /r/ constitutes 50\% of word-final singleton consonants in French child-directed speech (Demuth \& Culbertson, 2005). Thus, although one might wonder if segmental frequency would play a role in determining the acquisition of French word-final consonants, the later acquisition of liquids, and $/ \mathrm{r} /$ in particular, appears to be due to segmental problems rather than effects of low frequency.

In a longitudinal study of the child Suzanne, Demuth and Johnson (2003) found that the first word-final consonants appeared at 1;7. Before that time the child used reduplication of the first syllable $\left(\mathrm{C}_{1} \mathrm{VC}_{2}>\mathrm{C}_{1} \mathrm{VC} V \mathrm{~V}\right)$, and then truncation of the word-final consonant, producing subminimal, $\mathrm{CV}$ words. Thus, if word-final consonants were initially syllabified as onsets to empty-headed syllables, they then appear to have gone through a stage of development where they were disallowed altogether. In a longitudinal study of two children learning Québec French, Rose found that word-final consonants appeared before word-internal codas (word-final: Clara 1;7.6, Theo 2;4.6; word-medial: Clara 2;3.19, Theo 3;7.6). Following Goad \& Brannen (2003), Rose suggests that this provides evidence for the earlier acquisition of onsets to empty-headed syllables and the later acquisition of more marked coda consonants. Further support for the onset status of wordfinal consonants comes from the fact that many of these are aspirated, a characteristic that Goad and Brannen (2003) claim provides evidence of onset status. Unlike other word-final consonants, Clara's first word-final $[\mathrm{b}]$ appeared 8 months after her other word-final consonants, at the same time as her word-internal $[\mathrm{K}]$. Rose (2000) suggests that this provides evidence that Clara treats word-final [ $\mathrm{B}]$ as a coda consonant. However, given the experimental findings discussed above, where $/ \mathrm{r}$ / proves difficult for many children, it is possible that Clara's early problems with [в] in word-final position have more to do with segmental rather than syllabic/representational factors (see Goad \& Buckley (2005) for further discussion of Clara's $[\mathrm{B}])$. 
In sum, results from the experimental study show that 2-year-old French-speaking children produce singleton word-final consonants with a high degree of accuracy on familiar words. However, they also produce more word-final consonants in monosyllables (as compared with bisyllables), and are most accurate on voiceless stops (as compared with liquids). Given the later acquisition of word-final liquids, and the possible segmental problems with $/ \mathrm{r} /$, we might expect OL clusters to reduce to the obstruent rather than the liquid. Note, however, that these predictions have little to say about the syllabic status of word-final consonants or clusters.

\section{The acquisition of consonant clusters}

Much of the previous research on the acquisition of consonant clusters has been carried out in English, and this has generally focused on word-initial clusters (e.g., Templin, 1957; Chin \& Dinnsen, 1992; Smit, 1993; Barlow, 1997; 2001; Gierut, 1999; 2001; Pater \& Barlow, 2003; Gnanadesikan, 2004; Goad \& Rose, 2004). Much of this research has examined children's consonant cluster reduction patterns, and whether these are best explained by sonority (e.g., Ohala, 1999; Pater \& Barlow, 2003; Gnanadesikan, 2004), headedness (Goad \& Rose, 2004), or directionality, (i.e., whether $\mathrm{C} 1$ or $\mathrm{C} 2$ is more likely to be preserved (Lleó \& Prinz, 1996); see also Fikkert \& Freitas, 2004).

However, there has been little discussion of how and when clusters in wordfinal position are acquired (Kehoe \& Lleó, 2003; Salidis \& Johnson, 1997). Those studies that have addressed the issue suggest a tendency for word-final clusters to be acquired before word-initial clusters. For example, Templin (1957) found that English-speaking children aged 3;0, and 3;6 produced word-final clusters more accurately than word-initial clusters. Likewise, Lleó and Prinz (1996) found that German-speaking children between the ages 0;9-2;1 acquired word-final clusters several months before word-initial clusters. Boersma and Levelt (1999) also found that the majority of Dutch-speaking children in their study (aged $1 ; 0-1 ; 11$ ) acquired word-final clusters before word-initial clusters.

As Kirk and Demuth (2005) point out, this finding is surprising given that wordfinal singletons are typically acquired after word-initial singletons. That is, there is a universal tendency for the earliest syllable shape to be the unmarked CV, not the more marked VC. One concern with these earlier studies, however, is that they did not control for segmental content when making comparisons between word-initial and word-final clusters. Because certain consonantal sequences are acquired before others, differences related to segmental content may be accounting for some of the apparent differences between word-initial and word-final position. Kirk and Demuth (2005), therefore, explored the effect of word position on cluster development with identical segmental sequences. For example, they compared initial /s/+stop sequences (e.g., school) with final stop+/s/ clusters (e.g., box). These were also identical in structural complexity. Consistent with earlier research, they observed that Englishspeaking children produced word-final clusters more accurately than word-initial clusters. They suggest this may be due to the fact that word-final stop+/s/ clusters 
are four times more frequent than word-initial /s/+stop clusters. However, they also noted that articulatory factors (i.e. producing certain $\mathrm{CC}$ sequences) may play a role in the easier production of word-final stop+/s/ and nasal +/s/ clusters as compared to word-final nasal + stop clusters (where final voiced stops tend to delete, e.g., hand $>$ han) and /s/+stop clusters (which children often metathesize, e.g,, ask $>$ aks, wasp $>$ waps). Thus, word-final clusters appear to be acquired earlier in Germanic languages than word-initial clusters, possibly due to frequency factors, and the order of acquisition of different word-final clusters may be partially determined by articulatory or morphological factors. One of the goals of this study is to determine if French-speaking children also show earlier acquisition of wordfinal clusters as compared to word-initial clusters of the same segmental sequence when frequency and morphology are held constant.

Clues to the syllabification of French clusters in children's early productions may come from some of the errors made. We therefore also wanted to determine if word-final clusters are subject to the same error patterns as word-initial clusters. Certain types of error patterns occur more frequently in certain syllable positions. For example, it has been reported that deletion of both consonants of a cluster is common word finally, but less common for onsets, at least for English (e.g., Chin \& Dinnsen, 1992; Smit, 1993). This is consistent with universal markedness constraints requiring syllables to have onsets but not codas. Furthermore, the SSP prefers onsets to be less sonorant (e.g. obstruents), and codas to be more sonorant, creating a flat sonority gradient within the rhyme (e.g., Clements, 1990). If wordfinal OL clusters simplify to the stop, this might be more consistent with an onset rather than a coda analysis, since obstruents are typically assumed to be the unmarked form for onsets. Alternatively, if word-final OL clusters simplify to the liquid, this might be more consistent with a coda analysis, since sonorants are typically assumed to be the unmarked form for codas. Such analyses would also be consistent with Plénat's (1987) view of syllabification in French, which allows sonorant codas but not obstruent ones. In addition, epenthesis within a cluster (e.g., black $->$ [bəlæk]) appears to be a pattern more frequently reported for complex onsets than for complex codas (e.g., hand -> ?[hænəd]) (Bernhardt \& Stemberger, 1998). If cluster epenthesis is found word-finally, this would suggest that these clusters are prosodified as syllable onsets. Finally, we also wanted to examine children's productions for the phonetic features proposed by Goad and Brannen (2003) that might indicate onset syllabification (e.g., word-final epenthesis, final aspiration, nasal release, final consonant lengthening, or postvocalic pause).

In the present study we compare the acquisition of word-initial OL clusters with word-final OL clusters in French, focusing specifically on the relative order of acquisition and the types of errors made. Given the literature reviewed above, it is not clear if order of acquisition will tell us much about the structure of clusters, since both codas and onsets to empty-headed syllables may be considered 'marked', and therefore later acquired. However, we expect that segmental factors $([\mathrm{B}]$ is acquired late), articulatory factors (difficulty of producing certain consonant sequences), sonority factors, or structural factors may all play a role in determining the course of French word-final cluster acquisition. Issues of frequency should 
not play a major role in determining children's order of acquisition of word-initial and word-final OL clusters in French, since both occur with approximately the same frequency ${ }^{1}$.

\section{The Study}

\subsection{Subjects}

The database for this study consists of experimental cross-sectional data from monolingual French-speaking children growing up in Lyon, France. Subjects include 14 French-speaking children aged $1 ; 10$ to $2 ; 9$ years (mean age $=2 ; 4$ ). Seven children were boys and seven were girls.

\subsection{Procedure}

Children were engaged in semi-formal word elicitation tasks in two sessions of 30 minutes, recorded in the children's homes. The children played with an experimenter and, on occasion, with a parent. Tasks involved naming pictures in a book or picking objects out of a bag. Standard phrases used to elicit responses included Qu'est-ce que c'est? 'What is this?' and Qu'est-ce qu'il y a dans le sac? 'what is there in the bag?' The children were both audio and video-recorded using a digital camera and a FM transmitter/receiver microphone set-up.

\subsection{Stimuli}

The stimuli consisted of monosyllabic and disyllabic real words containing OL clusters in word-initial and word-final position ${ }^{2}$. Every attempt was made to choose pictureable words which would be familiar to two-year-old children, resulting in more word-initial than word-final clusters targeted in the stimulus set (21 vs. 14). Children were encouraged to produce the designated stimulus items, but any word containing an OL cluster that was spontaneously produced during a test session was included in the final data-set. A list of stimulus items is given in the Appendix and examples are shown in (8). Words featured with an asterisk in the Appendix are those that were not directly targeted as stimuli.

1. Of the $10,187,533$ French word tokens with OL clusters drawn from the BRULEX online dictionary, $44 \%$ occurred in word-initial position and $56 \%$ occurred in word-final position. Although it is not clear how closely this distribution matches that of child-directed speech, we expect that the frequency of OL clusters children hear may be approximately evenly distributed across word-initial and word-final positions. We thank Yvan Rose for providing the data for this analysis.

2. One of the word-final OL clusters was, in fact, a three-element cluster /rbr/ as in the word arbre. Children exhibited similar behavior with arbre as with the other stimulus items, justifying its inclusion. Children's reductions of final /rbr/ showed two patterns: deletion (arbre /авbь/ -> [ab]) or preservation of the initial /r/ (arbre /авьь/ -> [авb]). 
(8) Examples of French stimulus words containing OL clusters

a. Word-initial

/Ol/ clé /kle/ 'key', bleu /blø/ 'blue'

/Or/ bras /bьa/ 'arm', bracelet /bьasle/ 'bracelet'

b. Word-final

/Ol/ sable /sabl/ 'sand', table /tabl/ 'table'

/Or/ livre /livь/ 'book', coffre /kof в/ 'trunk, suitcase'

\subsection{Database and Data Coding}

The recorded sessions were downloaded onto a computer and transcribed into CHILDES database format including both target items and broad phonetic transcription. All productions of stimulus words were transcribed by two native speakers. Differences in transcription were resolved via consensus. If the two transcribers failed to agree, the production was excluded. This occurred for two items in the database. Multiple repetitions of the same stimulus item were included in the analysis. Productions which were inaudible or masked by noise were excluded. Productions were classified as to whether they were spontaneous or imitated (followed an adult production of the target word). Imitated utterances constituted 34\% of the total number of utterances. Paired t-tests revealed that there were no significant differences between the percent correct scores for OL clusters in imitated versus spontaneous productions (compare $46 \%$ vs. 53\%). Consequently, imitated and spontaneous productions were analyzed together.

Note that there is a potential confound between word-initial and word-final position. As mentioned above, stress is predictable in French: word-final syllables receive main stress. Thus, word-final OL clusters are always situated in stressed syllables, whereas word-initial OL clusters may occur in stressed or unstressed syllables depending upon whether the target production is monosyllabic (e.g., frite [f sit] 'potato chip') or multisyllabic (e.g., frigo [f si'go] 'fridge'). In order to determine whether word-initial clusters were influenced by the effect of stress, we compared the percent correct scores for the word-initial OL clusters in monosyllabic and in multisyllabic productions. In this analysis, we focused only on word-initial /Or/ clusters since very few multisyllabic words with word-initial/Ol/ clusters were present in the data-base. Paired t-tests revealed no significant differences between the percent correct scores for word-initial /Or/ clusters in monosyllabic versus multisyllabic productions (compare $48 \%$ vs. $50 \%$ ). Consequently the effect of stress was not taken into consideration in the analysis of word-initial OL clusters. It is possible that stress, which typically increases syllable duration, primarily effects the production of consonants within the rhyme (Kirk \& Demuth, 2006).

Productions were coded as correct if the child produced an OL sequence for a target OL cluster. Therefore, substitutions of an obstruent by an obstruent, or a liquid by a liquid were still considered correct (Word-initial: brosse $->$ [kвəs]; frites $->$ [flit]; Word-final: pantoufle -> [pãtusl]). Substitutions in which an obstruent or a liquid were replaced by another manner class were not considered correct 
(word-initial: cle -> [lje]). Occasionally, French children substituted /Or/ with Ow sequences (only in word-initial position). These cases were not counted as errors when additional analyses indicated that singleton $/ \mathrm{r} / \mathrm{s}$ were also produced as [w]. These cases were not frequent in the data. Deletions of either the obstruent, the liquid or of both consonants were considered incorrect (Word-initial: frigo $->$ [figo]; bras $->$ [ва]; crayon $->$ [ејо̃)]; Word-final: table $->$ [tab]; tigre $->$ [tів]; livre $->$ [li]). Forms with word-final vowel epenthesis were coded as correct when the OL sequence was realized. Given that a possible representation for word-final OL sequences is that of onset, the realization of a word-final vowel may be the spelling out of the empty nucleus position (see 5.4 for further discussion of these forms).

The final database consisted of 404 productions of target word-initial OL clusters and 222 productions of target word-final OL clusters. On average, there were 29 productions of word-initial clusters (range 7-45) and 16 productions of word-final clusters (range 7-22) per child.

\section{Results}

\subsection{Order of Acquisition: Word-initial vs. Word-final}

In the first analysis, we examine whether word-final OL clusters are acquired at the same time as word-initial OL clusters. Because we are using cross-sectional data, Order of Acquisition is inferred from overall percent correct scores. The means and standard deviations of percent correct scores for word-initial and wordfinal OL clusters for all French-speaking children are presented in Table $1 .^{3}$ The results show that children performed better with word-initial as compared to wordfinal OL clusters. Paired t-tests revealed that this difference was significant $(\mathrm{p}<0.05)$.

Table 2 compares the percent correct scores for word-initial and word-final OL clusters for individual French-speaking children. An examination of the individual findings indicated that eight of the 14 children performed better with word-initial as compared to word-final clusters. By «better» we use an informal metric of a $10 \%$ difference in percent score. Five children $(\mathrm{Ag}, \mathrm{El}, \mathrm{Qu}, \mathrm{Je}, \mathrm{Le})^{4}$ performed similarly with both sets of clusters. However, two of these performed almost at ceiling (Ag, El), and two others exhibited floor effects (Je, Le). Thus, only one child (Ar) actually performed better with word-final as compared to word-initial clusters. This child also displayed many instances of word-final epenthesis, a pattern that will be discussed in 5.4.

The group findings, therefore, show that word-final clusters were acquired later than word-initial clusters. Thus, at the point where children have the capacity to produce branching onsets, they lag in the production of word-final clusters of comparable segmental content. If word-final clusters are syllabified as codas, their later

3. The means presented in Table 1 represent the arithmetic mean of all the individual children's percent scores.

4. Because of the small number of productions, we count Le as a child who performed similarly in both word-initial and word-final position even though technically there is a difference of greater than $10 \%$ in favor of word-final clusters. 
Table 1. Means and standard deviations of percent correct scores for word-initial and word-final OL clusters for all French-speaking children.

\begin{tabular}{lcc}
\hline & Word-initial Clusters & Word-final Clusters \\
\hline Mean & 53 & 36 \\
Sd & 33 & 36 \\
\hline
\end{tabular}

Table 2. Comparison of percent correct scores for word-initial and word-final OL clusters for individual French-speaking children.

\begin{tabular}{lcc}
\hline Children & Word-initial & Word-final \\
\hline $\mathrm{Lo}$ & $97 \%(35 / 36)$ & $82 \%(14 / 17)$ \\
$\mathrm{Im}$ & $95 \%(20 / 21)$ & $67 \%(8 / 12)$ \\
$\mathrm{Ag}$ & $91 \%(41 / 45)$ & $96 \%(20 / 21)$ \\
$\mathrm{El}$ & $86 \%(30 / 35)$ & $94 \%(17 / 18)$ \\
$\mathrm{My}$ & $76 \%(16 / 21)$ & $19 \%(3 / 16)$ \\
$\mathrm{Cl}$ & $70 \%(14 / 20)$ & $29 \%(6 / 21)$ \\
$\mathrm{Ba}$ & $59 \%(23 / 39)$ & $5 \%(1 / 19)$ \\
$\mathrm{Pa}$ & $35 \%(11 / 31)$ & $6 \%(1 / 16)$ \\
$\mathrm{Ar}$ & $34 \%(12 / 35)$ & $60 \%(12 / 20)$ \\
$\mathrm{Ta}$ & $36 \%(5 / 14)$ & $0 \%(0 / 9)$ \\
$\mathrm{Qu}$ & $21 \%(7 / 33)$ & $22 \%(2 / 9)$ \\
$\mathrm{Mr}$ & $35 \%(11 / 31)$ & $7 \%(1 / 15)$ \\
$\mathrm{Je}$ & $14 \%(5 / 35)$ & $5 \%(1 / 22)$ \\
$\mathrm{Le}$ & $0 \%(0 / 7)$ & $14 \%(1 / 7)$ \\
\hline
\end{tabular}

acquisition could be related to violations of the SSP. If, however, these are syllabified as onsets, this could be explained in terms of the later acquisition of onsets to empty-headed syllables. Alternatively, these clusters might be prosodified across the syllable boundary, with the first consonant of the cluster being prosodified as a coda, and the second consonant prosodified as an onset. Thus, factors related to the sequence being both a coda and an onset to an empty-headed syllable might come into play. On the other hand, perhaps segmental or articulatory issues play a role. In the next section we consider the major error patterns made.

\subsection{Analysis of Error Patterns}

In this section, we examine whether word-final OL clusters display similar types of error patterns to word-initial OL clusters. We categorized error patterns into four types (preservation of $\mathrm{C}_{1}$ (obstruent), preservation of $\mathrm{C}_{2}$ (liquid), deletion of both $\mathrm{C}_{1}$ (obstruent) and $\mathrm{C}_{2}$ (liquid), and Other) as shown in (9). 
(9) Main error patterns in the data
Word-initial
Word-final
1. Preservation of $\mathrm{C}_{1}$ fromage $->$ [fo'maz]
tigre $->$ tig]
2. Preservation of $\mathrm{C}_{2}$ fromage $->$ [во'ma3]
tigre $\rightarrow$ [tік
3. Deletion of $\mathrm{C}_{1} \mathrm{C}_{2}$ fromage $->$ [o'ma3]
4. Other
fromage $->$ [mo'ma3]
tigre $\rightarrow[\mathrm{tii}]$
tigre $\rightarrow$ [tin]

The Other category contained error patterns that could not be categorized easily. This included deletions, in which it was difficult to determine whether $\mathrm{C}_{1}$ or $\mathrm{C}_{2}$ was being preserved (e.g., grenouille $->$ [nunuj]; tigre $->$ [tin]); substitutions, in which there was preservation of something other than an OL cluster (bras $->$ [вша]), and productions involving metatheses (e.g., coffre $->$ [f воk]). Although we had predicted that cluster epenthesis (vowel insertion between the two consonants of the cluster) as an error pattern may prove useful in providing information on the representation of word-initial and word-final clusters, only two cases were attested in the entire data base (both in word-initial position). These cases were also categorized as «other».

The distribution of error patterns is presented in Table 3. The findings clearly show that the most frequent error pattern in both word positions was preservation of $\mathrm{C}_{1}$ (obstruent). Preservation of $\mathrm{C}_{2}$ (liquid) was a minority pattern in both word positions. Deletion of both $\mathrm{C}_{1}$ and $\mathrm{C}_{2}$ was slightly more common in wordfinal as opposed to word-initial position (compare $12 \%$ vs. $7 \%$ ); however, a chisquare analysis revealed this difference was not significant $\left(\chi^{2}(1)=0.971, p>0.05\right)$. The percentages of error patterns categorized as «other» were low in both word positions.

In sum, although word-final clusters were acquired later than word-initial clusters, there was a tendency to preserve obstruents in both positions and there was no evidence of cluster epenthesis. If word-final clusters were represented as codas, we might have anticipated a higher proportion of full deletions or the presence of other error patterns that distinguish word-final from word-initial position. Recall, however, that 2-year-old French-speaking children are already producing single-

Table 3. Error analysis of word-initial versus word-final clusters.

\begin{tabular}{lcc}
\hline & Word-initial & Word-final \\
\hline Preservation of $\mathrm{C}_{1}$ & $72 \%(126)$ & $68 \%(92)$ \\
Preservation of $\mathrm{C}_{2}$ & $9 \%(16)$ & $13 \%(17)$ \\
Deletion of $\mathrm{C}_{1} \mathrm{C}_{2}$ & $7 \%(13)$ & $12 \%(16)$ \\
Other & $11 \%(19)$ & $7 \%(10)$ \\
Total $^{\mathrm{a}}$ & 174 & 135 \\
\hline
\end{tabular}

a. Total refers to the total number of errors. 
ton coda consonants at this time, so it would be unlikely for full deletion to take place. Furthermore, they are best at producing word-final singleton obstruents, and worse at producing liquids. Under the hypothesis that French only permits sonorant codas (Plénat, 1987) one might propose that the deleted liquids represent later acquired codas and the earlier produced obstruents represent onsets to empty-headed syllables, though we suggest that support for such a proposal in the children's productions is not clear. There were, however, some segmental asymmetries that may help explain the pattern of results found in this study. We explore this further below.

\subsection{Segmental Effects}

One of the findings from previous research on singleton word-final consonants is that many children perform poorly on liquids in general, and on $/ \mathrm{r} /$ in particular (e.g., Smit, 1993). We therefore explore children's performance on /Ol/ versus /Or/ clusters to determine whether children experience particular difficulty with /Or/ clusters, suggestive of segmental problems. Table 4 presents the means and standard deviations of word-initial and word-final /Ol/ versus /Or/ clusters for all the Frenchspeaking children in this study. The results show that children performed better with /Ol/ as opposed to /Or/ clusters in both word-initial and word-final position. Paired t-tests revealed that the difference in word-initial position was statistically significant $(\mathrm{p}<0.01)$ whereas the difference in word-final position was not significant or only marginally so $(\mathrm{p}=0.08)$.

Table 5 compares percent correct scores for word-initial and word-final /Ol/ and /Or/ clusters for individual French-speaking children. Employing the informal metric of a $10 \%$ difference in percent correct score (see above), nine children can be identified as displaying an asymmetry between /Ol/ versus /Or/ clusters in wordinitial position (El, My, $\mathrm{Cl}, \mathrm{Ba}, \mathrm{Pa}, \mathrm{Ar}, \mathrm{Ta}, \mathrm{Qu}$ and $\mathrm{Mr}$ ). Six of these children $(\mathrm{Cl}$, $\mathrm{Ba}, \mathrm{Pa}, \mathrm{Ar}, \mathrm{Qu}$, and $\mathrm{Mr}$ ) also displayed an asymmetry between /Ol/ and /Or/ clusters in word-final position, although, admittedly, the results are tentative because several of them produced very few word-final clusters. When they did produce clusters, however, these tended to be /Ol/ and not/Or/ clusters. With respect to the remaining three children who displayed an asymmetry in word-initial but not in word-final position, their results are inconclusive. The first child (TA) did not produce any word-final /Ol/ clusters; hence, his data can not be used to provide information on word-final clusters. The second child (El) performed well with both /Ol/ and /Or/ word-final clusters, suggesting ceiling effects may be the reason for why

Table 4. Means and standard deviations of percent correct scores for word-initial and wordfinal /Ol/ versus /Or/ clusters for all French-speaking children.

\begin{tabular}{lllll}
\hline & \multicolumn{2}{l}{ Word-initial Clusters } & \multicolumn{2}{l}{ Word-final Clusters } \\
& Ol & Or & Ol & Or \\
\hline Mean & 67 & 47 & 50 & 36 \\
Sd & 35 & 35 & 37 & 36 \\
\hline
\end{tabular}


Table 5. Comparison of percent correct scores for word-initial and word-final /O1/ versus /Or/ clusters for individual French-speaking children.

\begin{tabular}{lcccc}
\hline & \multicolumn{2}{l}{ Word-Initial Clusters } & \multicolumn{2}{l}{ Word-Final Clusters } \\
Child & Ol & Or & Ol & Or \\
\hline $\mathrm{Lo}$ & $90 \%(9 / 10)$ & $100 \%(26 / 26)$ & $75 \%(6 / 8)$ & $89 \%(8 / 9)$ \\
$\mathrm{Im}$ & $100 \%(8 / 8)$ & $92 \%(12 / 13)$ & $66 \%(2 / 3)$ & $67 \%(6 / 9)$ \\
$\mathrm{Ag}$ & $89 \%(16 / 18)$ & $93 \%(25 / 27)$ & $100 \%(9 / 9)$ & $92 \%(11 / 12)$ \\
$\mathrm{El}$ & $100 \%(7 / 7)$ & $82 \%(23 / 28)$ & $100 \%(4 / 4)$ & $93 \%(13 / 14)$ \\
$\mathrm{My}$ & $100 \%(7 / 7)$ & $64 \%(9 / 14)$ & $10 \%(1 / 10)$ & $33 \%(2 / 6)$ \\
$\mathrm{Cl}$ & $80 \%(4 / 5)$ & $67 \%(10 / 15)$ & $40 \%(4 / 10)$ & $18 \%(2 / 11)$ \\
$\mathrm{Ba}$ & $100 \%(15 / 15)$ & $33 \%(8 / 24)$ & $13 \%(1 / 8)$ & $0 \%(0 / 11)$ \\
$\mathrm{Pa}$ & $50 \%(4 / 8)$ & $29 \%(7 / 24)$ & $20 \%(1 / 5)$ & $0 \%(0 / 11)$ \\
$\mathrm{Ar}$ & $67 \%(6 / 9)$ & $23 \%(6 / 26)$ & $100 \%(5 / 5)$ & $47 \%(7 / 15)$ \\
$\mathrm{Ta}$ & $50 \%(3 / 6)$ & $25 \%(2 / 8)$ & - & $0 \%(0 / 9)$ \\
$\mathrm{Qu}$ & $35 \%(7 / 20)$ & $0 \%(0 / 13)$ & $40 \%(2 / 5)$ & $0 \%(0 / 4)$ \\
$\mathrm{Mr}$ & $83 \%(5 / 6)$ & $24 \%(6 / 25)$ & $33 \%(1 / 3)$ & $0 \%(0 / 12)$ \\
$\mathrm{Je}$ & $0 \%(0 / 10)$ & $20 \%(5 / 25)$ & $0 \%(0 / 5)$ & $6 \%(1 / 17)$ \\
$\mathrm{Le}$ & $0 \%(0 / 1)$ & $0 \%(0 / 6)$ & - & $14 \%(1 / 7)$ \\
\hline
\end{tabular}

an asymmetry was not observed in word-final position. The third child (My) actually performed better with /Or/ as opposed to /Ol/ word-final clusters; however, he produced very few words with word-final /Or/ clusters making these results also tentative. In sum, although the group data did not support a statistically significant difference between /Ol/ versus /Or/ clusters in word-final position, the fact that the same group of children displayed an asymmetry between /Ol/ vs. /Or/ clusters in both word positions, suggests a noteworthy trend in this direction. Kehoe, HilaireDebove, Demuth, and Lleó (submitted) suggest that this may be due to segmental problems with /r/. Recall that Rose (2000) also found significant problems with the acquisition of singleton $/ \mathrm{r} /$, suggesting that some children represent it as coda, and others as an onset to an empty-headed syllable. The fact that /r/ posed a problem in singleton codas and in word-initial and word-final clusters, leads us to believe that segmental rather than structural factors underlie its late acquisition.

\subsection{Epenthesis and Consonant Lengthening}

In this analysis, we examine the phonetic production patterns of word-final singleton and OL clusters in order to determine whether there is support for an onset syllabification of these structures (cf. Goad \& Brannen, 2003). Word-final vowel epenthesis was frequently observed in our data, occurring in $11 \%(24 / 222)$ of the productions containing word-final OL clusters. It was attested in eight children's productions but two children (Ag and $\mathrm{Ar}$ ), in particular, displayed several examples of word-final epenthesis, with both singleton consonants and with OL clusters in the 
elicited production task. Examples are given in (10), suggesting a possible onset syllabification for these items.

(10) Examples of epenthesis in Ar and Ag's productions

a. Word-final singleton consonants

\begin{tabular}{|c|c|c|c|c|c|}
\hline e & 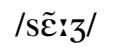 & 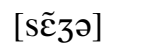 & 'monkey' & $\mathrm{Ar}$ & $2 ; 6,08$ \\
\hline lune & /lyn/ & [nynə] & 'moon' & $\mathrm{Ar}$ & $2 ; 6,08$ \\
\hline me & /fãtom/ & [fã'tomə] & 'ghost' & $\mathrm{Ar}$ & $2 ; 6,08$ \\
\hline e & /kyb/ & [kybə] & 'block' & $\mathrm{Ar}$ & $2 ; 6,11$ \\
\hline ile & /e'twal/ & [er'twalə] & 'star' & $\mathrm{Ar}$ & $2 ; 6,11$ \\
\hline ade & /salad/ & [sa'ladə] & 'lettuce' & $\mathrm{Ag}$ & $2 ; 1,08$ \\
\hline & /vag/ & [bagə] & 'wave' & $\mathrm{Ag}$ & $2 ; 1,08$ \\
\hline hine & /ma'Jin/ & [ma'Sinə] & 'machine' & $\mathrm{Ag}$ & $2 ; 1,22$ \\
\hline
\end{tabular}

b. Word-final OL clusters

\begin{tabular}{|c|c|c|c|c|c|}
\hline sable & /sabl/ & [slablə] & 'sand' & $\mathrm{Ar}$ & $2 ; 6,11$ \\
\hline table & /tabl/ & [tablø] & 'table' & $\mathrm{Ar}$ & $2 ; 6,11$ \\
\hline$\underline{\text { liv }}$ & /livь/ & [libьә] & 'book' & $\mathrm{Ar}$ & $2 ; 6,11$ \\
\hline chambre & / /ãbь/ & [ & 'bedroom' & $\mathrm{Ar}$ & $2 ; 6,11$ \\
\hline tigre & /tigв/ & [tigə] & 'tiger' & $\mathrm{Ar}$ & $2 ; 6,11$ \\
\hline sable & /sabl/ & [sablə] & 'sand' & $\mathrm{Ag}$ & $2 ; 1,22$ \\
\hline 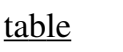 & /tabl/ & [tablə] & 'table' & $\mathrm{Ag}$ & $2 ; 1,22$ \\
\hline ble & /møbl/ & [mœblə] & 'furniture' & $\mathrm{Ag}$ & $2 ; 1,22$ \\
\hline
\end{tabular}

Recall that Ag performed almost at ceiling on word-final clusters, obtaining $96 \%$ accuracy, the highest of any of the children in the study. Perhaps his use of word-final epenthesis helped him to prosodify word-final onsets. Recall also that Ar was the only child in the study to exhibit significantly better performance of word-final clusters (60\% correct) than word-initial clusters ( $34 \%$ correct). Again, we suggest that her extensive use of word-final epenthesis may facilitate earlier prosodic licensing of word-final clusters.

Another phonetic pattern observed in the data was final consonant lengthening when the liquid consonant of the cluster was not produced. Although this happened only with the fricative obstruents /f/ and /v/, consonant lengthening tended to occur in the productions of children who did not produce many word-final clusters. Goad and Brannen (2003) might take consonant lengthening to be evidence that these word-final consonants are functioning as onsets to empty-headed syllables. However, we suggest that consonant lengthening with these fricative obstruents may have been children's best attempt at producing a cluster at these early stages of cluster production, indicating either compensatory lengthening to make up for the omitted liquid, or articulatory difficulty (cf. Demuth, et al., in press). 
(11) Examples of final consonant lengthening in the French children's productions

$\begin{array}{llllll}\underline{\text { coffre }} & \text { /kof } / & \text { [kof:] } & \text { 'chest, trunk' } & \text { Le } & 1 ; 10,08 \\ \underline{\text { livre }} & / \text { livı/ } & \text { [liv:] } & \text { 'book' } & \text { Le } & 1 ; 10,08 \\ \underline{\text { livre }} & / \text { livı/ } & \text { [lif:] } & \text { 'book' } & \text { My } & 2 ; 7,04 \\ \text { pantoufle } & / \text { pã'tufl/ } & \text { [pã'tuf:] } & \text { 'slipper' } & \text { Ba } & 2 ; 9,00 \\ \underline{\text { coffre }} & / \text { kof } / & \text { [kof:] } & \text { 'chest, trunk' } & \text { Ba } & 2 ; 9,00\end{array}$

In this section we have shown that most French-speaking 2-year-olds are more accurate at producing word-initial OL clusters in contrast to word-final OL clusters. Segmental problems with word-final $/ \mathrm{r} /$, which is often dropped or devoiced in the input children hear, may contribute to the later acquisition of OL clusters word-finally. However, the error patterns are similar in both positions, displaying a strong tendency to preserve the $\mathrm{C}_{1}$ (obstruent) consonants in cases of consonant cluster simplification. One possibility is that French-speaking children's representation of word-initial and word-final OL clusters is the same, both cluster simplifications preserving the unmarked (obstruent) consonant as an optimal onset (cf. Pater, 1997). Further support for an onset analysis of word-final clusters comes from the fact that some children exhibit word-final epenthesis. This would suggest that at least some French-speaking children assume an onset analysis for wordfinal OL clusters.

\section{Discussion}

The syllabic representation of French word-final consonants and clusters continues to be debated, raising question about how syllabic representations are acquired. This study compared the acquisition of French word-initial and word-final OL consonant clusters using elicited and spontaneous productions of known words from 14 French-speaking 2-year-olds. The results showed that most of the children were more accurate at producing word-initial clusters. This might be taken as evidence that word-final clusters are treated as codas, since these are typically acquired later than onsets. However, it is also possible that onsets to empty-headed syllables might be later acquired than onsets of syllables containing a full nucleus. Thus, the later acquisition of word-final as compared to word-initial OL clusters cannot necessarily be taken as evidence of syllabic representation.

Cluster reduction patterns were the same in both positions, with a tendency to preserve the obstruent. This might be taken as evidence that word-final clusters are onsets, where the unmarked choice is to preserve the least sonorous consonant. On the other hand, perhaps the liquid of OL clusters is deleted to avoid violations of the SSP, or, to avoid onsets to empty headed syllables (assuming the obstruent is syllabified as a coda and the liquid as an onset). However, there are a number of possible perceptual, segmental (problems with /r/), or articulatory (problematic segmental sequencing) explanations for these findings. First, since the obstruent of a word-final OL cluster is immediately preceded by a vowel, there might be better perceptual cues to the obstruent, leading to the increased preservation of $C_{1}$ in 
word-final position. Tentative support for such a proposal comes from preliminary findings from the longitudinal study of 2 children, where word-final LO clusters tend to preserve the liquid (McCullough \& Demuth, 2006). Second, there are several reasons why word-final liquids, especially /r/, might be deleted in children's early speech. On one hand, $/ \mathrm{r} /$ is often missing or devoiced in the OL clusters children hear, possibly leading to impoverished lexical representations. On the other hand, wordfinal singleton $/ \mathrm{r} /$ is acquired much later than other segments, suggesting that this segment is difficult to produce. In sum, the pattern of errors found in cluster reduction provides little evidence for syllabification.

Other error patterns are somewhat more informative, though they involved only a few children in this study. Three children showed lengthening of fricative obstruents in target word-final OL clusters, and two children showed numerous examples of final vowel epenthesis. Perhaps, for these children, word-final clusters were syllabified as onsets. Certainly this would appear to be the case for the children who used epenthesis, though Demuth, et al., (in press) argue that similar findings for English-speaking children may only be evidence of articulatory difficulty. Further longitudinal study might provide evidence as to how long this period of epenthesis lasts, and if all French-speaking children exhibit epenthesis at some point in development. This might also provide further evidence as to the possible variability that French-speaking children exhibit in producing word-final clusters, and how variable their representations might be.

One of the questions that arise is the generality of the findings presented here. Preliminary analysis from the longitudinal study of two other French-speaking children, also from Lyon, indicates that the patterns found in the present study may be quite robust. The two children (Marie, a girl, and Tim, a boy) both acquire wordinitial OL clusters several months before word-final OL clusters, replicating the majority pattern found in this study (McCullough \& Demuth, 2006). Furthermore, the primary error patterns for both word-initial and word-final OL clusters included the preservation of the $\mathrm{C}_{1}$ (obstruent), again replicating results from the present study (e.g., prendre /рьãdь/ [рrãd] 'take' (Marie 2;2;30); propre /рьэрь/ -> [рор] 'clean' (Marie 2;5,17); sucre /syku/ -> [syk] 'sugar' (Tim 1;10,05)). Thus, although there was no extensive use of epenthesis to provide evidence of syllabification it appears that the major patterns of acquisition found in the present cross-sectional data are also borne out in development.

\section{Conclusion}

This study found that 2-year-old French-speaking children performed better on elicited word-initial than on word-final OL clusters, suggesting that word-initial clusters are acquired first. This pattern of acquisition differs from that typically reported for Germanic languages, where word-final clusters are acquired first. There are several perceptual, segmental, and sonority factors that may influence this course of acquisition, including the delayed acquisition of /r/. However, the structural status of children's word-final clusters as either codas, onsets to an emptyheaded syllable, or both (O.L), is unclear. Given the ambiguous representational 
status of word-final consonants in French, we might expect individual variation in the types of syllabic representations children assume. Rose $(2000,2003)$ argued that word-final $/ \mathrm{s} / \mathrm{has}$ variable coda versus onset status in the grammars of the two children he studied who were learning Québec French. Perhaps this is also true for adults. In the present study, two children showed frequent use of epenthesis in both word-final singletons and clusters, suggesting that, at least for these children, wordfinal OL clusters may be prosodified as onsets. Future research will need to examine more comprehensively the acquisition of word-final singletons and clusters in French and other languages, and the extent to which the course of acquisition varies with different segmental content. This may help shed light on the reported order of cluster acquisition differences between Germanic languages and French. The present study identifies some of the methodological and theoretical issues to be addressed.

\section{Appendix}

\section{Stimuli}

\section{Word-initial clusters}

*blanc /blã/ 'white', bracelet /bьasle/ 'bracelet', bras /bьa/ 'arm', brosse /bьэs/ 'brush', brun /bьø̃ / 'brown', clé /kle/ 'key', clown /klun/ 'clown', crayon /kьعjõ/ 'crayon', crêpe /kьep/ 'pancake', fleur /flœв/ 'flower', flûte /flyt/ 'flute', fraise /f вєz/ 'strawberry', * framboise /f вãbwaz/ 'raspberry', frigo /f вigo/ 'fridge', frites /f вit/ 'french fries', fromage /f вотаз/ 'cheese', glace /glas/ 'icecream', grand /gвã/ 'big/tall', grenouille/gвәnuj/ 'frog', plage/plaz/ 'beach', tracteur/t ваktœь/ 'tractor', train /t $\mathrm{s} \tilde{\varepsilon} /$ 'train', trompette /t вõpet/ 'trumpet'.

\section{Word-final clusters}

arbre /авьь/ 'tree', autre /ot s/ 'other', chambre / /ãbs/ 'bedroom', chèvre / $/ \varepsilon v в /$ 'goat', coffre /kof s/ 'suitcase', *gaufre /gof $\mathrm{s} /$ 'waffle', livre /livs/ 'book', *meuble /mœbl/ 'furniture', montre /mõt $\mathrm{s} /$ 'watch', ongle /õgl/ 'fingernail', pantoufle /pãtufl/ 'slipper', sable /sabl/ 'beach', *spectacle/spektakl/ 'a production', sucre /syks/ 'sugar', table /tabl/ 'table', ventre/vãt s/ 'stomach', zèbre /zebs/ 'zebra'.

* = items not targeted as stimuli

\section{References}

Barlow, Jessica (1997). A Constraint-based Account of Syllable Onsets: Evidence from Developing Systems. Indiana University, doctoral dissertation.

- (2001). «The Structure of /s/-Sequences: Evidence from a Disordered System». Journal of Child Language 28: 291-324.

Bernhardt, Barbara; Stemberger, Joe (1998). Handbook of Phonological Development. From the Perspective of Constraint-based Nonlinear Phonology. San Diego: Academic Press. 
Boersma, Paul; Levelt, Clara (1999). «Gradual Constraint-Ranking Learning Algorithm Predicts Acquisition Order». In: Clark, Eve (ed.). Proceedings of the $30^{\text {th }}$ Child Language Research Forum. Stanford: CSLI. pp. 229-237.

Bouchard, Denis (1980). «A Voice for 'e muet». Journal of Linguistic Research 1:17-47. Casagrande, Jean (1984). The Sound System of French. Washington: Georgetown University Press.

Charette, Monik (1991). Conditions on Phonological Government. Cambridge: Cambridge University Press.

Chin, Steve; Dinnsen, Daniel (1992). «Consonant Clusters in Disordered Speech: Constraints and Correspondence Patterns». Journal of Child Language 19: 259-285.

Clements, George N. (1990). «The Role of the Sonority Cycle in Core Syllabification». In: Kingston, John; Beckman, Mary (eds.). Between the Grammar and Physics of Speech. Cambridge: Cambridge University Press, pp. 283-333.

Côté, Marie-Hélène (2000). Consonant Cluster Phonotactics: A Perceptual Approach. Massachusetts Institute of Technology, Cambridge, doctoral dissertation.

- (2004). «Consonant Cluster Simplification in Québec French». Probus 1: 151-201. Dell, François. (1973). Les règles et les sons. Paris: Hermann.

- (1995). «Consonant Clusters and Phonological Syllables in French». Lingua 95: 5-26.

Demuth, Katherine (1995). «Markedness and the Development of Prosodic Structure». In: Beckman, Jill. (ed.). Proceedings of the North East Linguistic Society 25. Amherst, MA: GLSA, University of Massachusetts, pp. 13-25.

Demuth, Katherine; Culbertson, Jennifer (2005). «The Acquisition of Word-final Consonants in French». Brown University, unpublished manuscript.

Demuth, Katherine; Culbertson, Jennifer; Alter, Jennifer (in press). «Word-minimality, Epenthesis, and Coda Licensing in the Acquisition of English». Language \& Speech.

Demuth, Katherine; Johnson, Mark (2003). «Truncation to Subminimal Words in Early French». Canadian Journal of Linguistics 48: 11-241.

Féry, Caroline (2003). «Markedness, Faithfulness, Vowel Quality and Syllable Structure in French». Journal of French Language Studies 13: 1-33.

Fikkert, Paula; Freitas, Maria João (2004). «The Role of Language-specific Phonotactics in the Acquisition of Onset Clusters». In: Cornips, Leonie; Doetjes, Jenny (eds.), Linguistics in the Netherlands 2004: 58-68.

Gierut, Judith. (1999). «Syllable Onsets: Clusters and Adjuncts in Acquisition». Journal of Speech, Language, and Hearing Research 42: 708-726.

- (2001). «Syllable Onsets II: Three-element Clusters in Phonological Treatment». Journal of Speech, Language, and Hearing Research 44: 886-904.

Gnanadesikan, Amalia (2004). «Markedness and Faithfulness Constraints in Child Phonology». In: Kager; Rene; Pater, Joe; Zonneveld, Wim (eds.). Constraints in Phonological Acquisition. Cambridge: Cambridge University Press.

Goad, Heather; Brannen, Kathleen (2003). «Phonetic Evidence for Phonological Structure in Syllabification». In: van de Weijer, Jeroen.; van Heuven, Vincent.; van der Hulst, Harry (eds.). The Phonological Spectrum, Vol. 2. Amsterdam: John Benjamins, pp. 3-30.

Goad, Heather; Buckley, Meaghen (2005). «Prosodic Structure in Child French: Evidence for the Foot». Ms., McGill University. 
Goad, Heather; Rose, Yvan (2004). «Input Elaboration, Head Faithfulness and Evidence for Representation in the Acquisition of Left-Edge Clusters in West Germanic». In: Kager, René; Pater, Joe; Zonneveld, Wim (eds.), Fixing priorities: Constraints in phonological acquisition. Cambridge, UK: Cambridge University Press.

Hammond, Michael (1999). The Phonology of English: A Prosodic Optimality-theoretic Approach. Oxford, UK: Oxford University Press.

Harris, John (1994). English Sound Structure. Oxford, Blackwell.

Hilaire-Debove, Geraldine; Kehoe, Margaret. (2004). «Acquisition des Consonnes Finales (Codas) chez les Enfants Francophones : des Universaux aux Spécificités de la Langue Maternelle». In Actes de la 25ème Journée d'Études sur la Parole. Fez: Moracco, pp. 265-268.

Kaye, Jonathan (1990). «Coda Licensing». Phonology 7: 301-330.

Kaye, Jonathan; Lowenstamm, Jean; Vergnaud, Jean-Roger (1990). «Constituent Structure and Government Phonology». Phonology 7: 193-231.

Kehoe, Margaret; Hilaire-Debove, Geraldine; Demuth, Katherine; Lleó, Conxita (submitted). «The Structure of Branching Onsets and Rising diphthongs: Evidence from the Acquisition of French and Spanish».

Kehoe, Margaret; Lleó, Conxita (2003). «The Acquisition of Syllable Types in Monolingual and Bilingual German and Spanish children». In: Beachley, Barbara; Brown, Amanda; Conlin, Frances (eds.). Proceedings of the 27th Annual Boston University Conference on Language Development. Somerville, MA: Cascadilla Press, pp. 402-413.

Kehoe, Margaret; Stoel Gammon, Carol (2001). «Development of Syllable Structure in English-speaking Children with Particular Reference to Rhymes». Journal of Child Language 28: 393-432.

Kirk, Cecilia; Demuth, Katherine (2005). «Asymmetries in the Acquisition of Wordinitial and Word-final Consonant Clusters». Journal of Child Language 32: 709-734.

- (2006). «Accounting for variability in 2-year-olds'production of coda consonants». Language Learning and Development 2, 97-118.

Lleó, Conxita; Prinz, Michael (1996). «Consonant Clusters in Child Phonology and the Directionality of Syllable Structure Assignment». Journal of Child Language 23: 31-56.

McCullough, Elizabeth; Demuth, Katherine (2006). «The Acquisition of Word-final Consonant Clusters in French». Brown University, unpublished manuscript.

Nikièma, Emmanuel (1999). «Government-licensing and Consonant Cluster Simplification in Québec French». Canadian Journal of Linguistics 44: 327-357.

Ohala, Diane (1999). «The Influence of Sonority on Children's Cluster Reductions.» Journal of Communication Disorders 32: 397-422.

van Oostendorp, Marc (2000). Phonological Projection. A Theory of Feature Content and Prosodic Structure. Berlin: Mouton de Gruyter.

Pater, Joe (1997). «Minimal Violation and Phonological Development». Language Acquisition 6: 201-253.

Pater, Joe; Barlow, Jessica (2003). «Constraint Conflict in Cluster Reduction». Journal of Child Language 30: 487-526.

Plénat, Marc (1987). «On the Structure of Rime in Standard French». Linguistics 25: 867-887. 
Prince, Alan; Smolensky, Paul (1993). Optimality Theory: Constraint Interaction in Generative Grammar. Cambridge: Technical report TR-2. Rutgers Center for Cognitive Science, Rutgers University.

Rialland, Annie (1994). «The Phonology and Phonetics of Extrasyllabicity in French». In: Keating, Pat (ed.). Phonological Structure and Phonetic Form. Papers in Laboratory Phonology 3. Cambridge: Cambridge University Press, pp. 136-159.

Rose, Yvan (2000). Headedness and Prosodic Licensing in the L1 Acquisition of Phonology. McGill University, doctoral dissertation.

- (2003). «Place Specification and Segmental Distribution in the Acquisition of Word-final Consonant Syllabification». Canadian Journal of Linguistics 48 (3/4): 409-435.

Salidis, Joanna; Johnson, Jacqueline (1997). «The Production of Minimal words: A Longitudinal Case Study of Phonological Development». Language Acquisition 6: $1-36$.

Scullen, Mary Ellen (1997). The Prosodic Morphology of French. Indiana Linguistics Club: Bloomington, doctoral dissertation.

Selkirk, Elisabeth (1972). The Phrase Phonology of English and French. MIT, doctoral dissertation (published in 1980 by Garland Publishing, New York).

Smit, Anna. (1993). «Phonologic Error Distribution in the Iowa-Nebraska Articulation Norms Project: Word-initial Consonant Clusters». Journal of Speech and Hearing Research 36: 931-947.

Stites, Jessica; Demuth, Katherine; Kirk, Cecilia (2004). «Markedness versus Frequency Effects in Coda Acquisition». In: Brugos, Anna; Micciulla, Linnea.; Smith, Christine E. (eds.), Proceedings of the 28th Annual Boston University Conference on Language Development. Somerville, MA: Cascadilla Press, pp. 565-576.

Templin, Mildred (1957). Certain Language Skills in Children: Their Development and Interrelationship (Monograph Series No. 26). Minneapolis: University of Minnesota, The Institute of Child Welfare.

Tranel, Bernard (1987). The Sounds of French. An Introduction. Cambridge: Cambridge University Press.

- (1995). «French Final Consonants and Non-linear Phonology». In: Durand, Jacques; Hintze, Marie-Anne (eds.). French Phonology: Morae, Syllables, Words, Lingua pp. 131-167. 